\title{
Age-Dependent Reductions in the Level of Glial Fibrillary Acidic Protein in the Prefrontal Cortex in Major Depression
}

\author{
Xiaohong Si', Jose Javier Miguel-Hidalgo', Gillian O’Dwyer', Craig A Stockmeier' and Grazyna Rajkowska*,' \\ 'Department of Psychiatry and Human Behavior, University of Mississippi Medical Center, Jackson, MS, USA
}

\begin{abstract}
The density of glial cells is reduced in certain layers of the dorsolateral prefrontal cortex in major depressive disorder (MDD). Moreover, there are reductions in the packing density of glial fibrillary acidic protein (GFAP) immunoreactive astrocytes in the same cortical layers in younger subjects with MDD. The objective of the present study was to test if the level of GFAP is preferentially decreased in younger subjects with MDD, and whether GFAP levels are correlated with the age of onset of depression. Post-mortem brain tissue punches from dorsolateral prefrontal cortex were collected from 15 subjects with MDD and 15 age-matched psychiatrically normal control subjects. Western blots were performed on gels containing duplicated samples from both subjects of each matched pair, and on gels containing samples at different ages from either the MDD or the control group. The GFAP level was calculated as the ratio of the optical density of GFAP bands to actin bands in subjects with MDD and nonpsychiatric controls. Levels of GFAP were significantly lower in subjects with MDD as compared to controls and this decrease was most prominent in subjects less than 60 years old at the time of death. In the MDD group, GFAP levels were positively correlated with age at the time of death and show a trend toward correlation with the age of onset of depression. These findings indicate that a decrease in levels of GFAP may contribute to the pathophysiology of MDD, particularly in subjects of relatively young age.

Neuropsychopharmacology (2004) 29, 2088-2096, advance online publication, 7 July 2004; doi: I 0. I 038/sj.npp. 1300525
\end{abstract}

Keywords: depression; glia; astrocytes; Western blotting; frontal lobe; aging

\section{INTRODUCTION}

Morphometric studies in post-mortem tissue report a reduction in glial cell number and density in pyramidal layers III and V of the frontal cortical areas in primary mood disorder, that is, major depressive disorder (MDD) and bipolar disorder (reviewed in Rajkowska, 2003). In MDD, a significant decrease in the density of Nissl-stained glial cells is observed within layers III and V of the dorsolateral prefrontal cortex (dlPFC, Brodmann area 9), as compared to psychiatrically normal age-matched control subjects (Cotter et al, 2002a; Rajkowska et al, 1999). In bipolar disorder, reductions in glial cell density are reported in deep layer III (Rajkowska et al, 2001). Glial cell reductions in mood disorders have also been reported in other areas of frontal cortex, such as: orbital prefrontal cortex (Rajkowska et al, 1999), subgenual cortex (Ongur et al, 1998), and anterior cingulate cortex (Cotter et al, 2001). In MDD, these reductions in glial cells appear to be

\footnotetext{
*Correspondence: Dr G Rajkowska, Department of Psychiatry and Human Behavior, Box 127, University of Mississippi Medical Center, 2500 N State Street, Jackson, MS 39216, USA, Tel: + 601 9845995 , Fax: + 60I 984 5899, E-mail: GRajkowska@psychiatry.umsmed.edu Received 26 February 2003; revised 26 May 2004; accepted I5 June 2004

Online publication: 16 June 2004 at http://www.acnp.org/citations/ Npp06 | 60404085/default.pdf
}

more consistent and of a larger magnitude than the pathology of neuronal cells (Cotter et al, 2002b; Cotter et al, 2001; Ongur et al, 1998; Rajkowska et al, 1999, 2001).

Studies suggest that astrocytes may be one of the glial cell types involved in the changes of glial cell numbers in depression, described above. Alterations in the density of immunoreactive astrocytes and the expression of the astrocytic marker glial fibrillary acidic protein (GFAP) have been identified in frontal cortex of subjects with MDD (Damadzic et al, 2001; Davis et al, 2002; Johnston-Wilson et al, 2000; Knable et al, 2001; Miguel-Hidalgo et al, 2000; Webster et al, 2001). A proteomic study in prefrontal area 10 revealed that the levels of four different isoforms of GFAP protein were significantly decreased in MDD (Johnston-Wilson et al, 2000). However, in this study, neither the laminar distribution of GFAP nor the number of GFAP immunoreactive astrocytes was analyzed. In contrast, in another morphometric study, GFAP immunoreactive astrocytes were analyzed in individual cortical layers of dorsolateral prefrontal area 9 in MDD (Miguel-Hidalgo et al, 2000). Although the packing density of astrocytes and the fraction of tissue covered by GFAP immunoreactive processes did not differ between depressed and control groups, there was a significant correlation between age and GFAP immunoreactivity among subjects with MDD. Younger (30-45 years old), as opposed to older (46-86 years 
old) subjects with MDD showed a significantly smaller area fraction of GFAP (ie the percentage of the measured area covered by immunopositive elements) and a reduction in the packing density of GFAP immunoreactive cells, in comparison to age-matched control subjects. In another study focusing on older subjects (over 60 years old), a significant increase in GFAP area fraction was found in MDD only in layer I of dorsolateral prefrontal cortex (areas 9 and 46) (Davis et al, 2002).

The present study examines the level of GFAP expression in the dorsolateral prefrontal cortex in subjects with MDD and in age-matched control subjects. The purpose of this study is to test whether the relative levels of GFAP examined by Western blot analysis are in the same direction as changes in the distribution of GFAP immunoreactive structures determined by cell morphometric methods (Miguel-Hidalgo et al, 2000). Moreover, the present study further assesses age-related changes in GFAP protein levels in the dorsolateral prefrontal cortex suggested by our previous studies.

\section{MATERIALS AND METHODS}

\section{Human Subjects}

Brain samples were collected at autopsy at the Cuyahoga County Coroner's Office in Cleveland, Ohio. Informed written consent was collected from the legal next-of-kin of all subjects. Next-of-kin were interviewed and retrospective psychiatric assessments were conducted in accordance with Institutional Review Board policies, as previously described (Miguel-Hidalgo et al, 2000; Rajkowska et al, 1999). A total of 15 subjects were diagnosed with MDD according to the Diagnostic and Statistic Manual of Mental DisordersRevised (DSM-III-R). Subjects met diagnostic criteria for depression within the last month of life. The remaining 15 subjects were assessed as free of neurological or psychiatric disorders, and thus considered normal control subjects. These control subjects were matched with the $15 \mathrm{MDD}$ subjects for age, gender, ethnicity, and post-mortem delay (see Table 1).

Among the 15 MDD subjects studied, 14 were individuals included in the previous GFAP immunohistochemical study (Miguel-Hidalgo et al, 2000) and one new subject (case \#3, Table 1) was added. Among the 15 control subjects, five analyzed in this study were the same subjects as the ones assessed previously (Miguel-Hidalgo et al, 2000) and the other 10 control cases were new subjects chosen to more closely match by age to MDD subjects. In the control group, two subjects had a prescription for clonazepam and two subjects had past histories of alcohol abuse (Table 1). Among the 15 depressed subjects, 12 had prescriptions for anxiolytic, antipsychotic, and/or antidepressant medication. During the last month of life, 10 subjects with MDD were taking antidepressant medication, seven subjects were taking an anxiolytic medication, and four subjects were taking antipsychotic medication. Toxicological assessment of blood at autopsy revealed the presence of an antidepressant drug in three subjects, an anxiolytic drug in three subjects, and an antipsychotic drug in one subject. One of the depressed subjects was alcohol dependent, however, no alcohol was detected in the blood at autopsy. One depressed subject had a history of alcohol dependence 10 years prior to death. One depressed subject had a history of alcohol abuse not current at the time of death, one of abuse of painkillers current at the time of death, and two of polysubstance abuse also current at the time of death (see Table 1).

There was no statistically significant difference between control group and MDD group in either age or post-mortem interval (PMI) (Table 1). However, there was a significant difference in the freezer storage time $\left(t_{14}=-3.092\right.$, $p=0.008)$.

\section{Tissue Preparation}

Blocks of tissue from the prefrontal cortex containing Brodmann's area 9 were frozen at autopsy and stored at $-80^{\circ} \mathrm{C}$ for $41-95$ months (see storage time in Table 1). The blocks were sectioned with a cryostat to obtain two $30 \mu \mathrm{m}$ sections. The sections were mounted on subbed slides, and stained with cresyl violet to visualize the cortical layers. Area 9 was outlined by cytoarchitectural criteria on these sections (Rajkowska and Goldman-Rakic, 1995). Sections from which tissue punches were taken, at a thickness of $50 \mu \mathrm{m}$, were immediately adjacent to the $30 \mu \mathrm{m}$ sections stained for Nissl. The diameter of the punches was adjusted to fit all six cortical layers of the gray matter of area 9; underlying white matter was excluded. The tissue punches after collection were homogenized on ice with a $1 \mathrm{ml}$ solution containing $1 \%$ sodium dodecyl sulfate (SDS), $2 \mathrm{mM}$ EDTA, $0.01 \mathrm{M}$ Tris-HCL, and $6 \mu \mathrm{l}$ fresh protease inhibitor (Complete Mini, Roche, Basel, Switzerland). The homogenizing solution was centrifuged at $4^{\circ} \mathrm{C}$ and $12000 \mathrm{~g}$ for $30 \mathrm{~min}$ and the supernatant was then stored at $-80^{\circ} \mathrm{C}$ until use.

The protein concentrations of the homogenized punches were assessed using the bicinchonic acid protein quantitation assay (Pierce Biotechnology, Rockford, Illinois).

\section{Western Blot}

Proteins in the supernatant were resolved by electrophoresis using the NuPAGE ${ }^{\circledR}$ Bis-Tris Electrophoretic System (Invitrogen, Carlsbad, California), and were transferred to polyvinylidine difluoride (PVDF) membranes. Varying amounts of protein were first analyzed with each antibody to identify the protein range that produced a linear detection response. Protein levels of GFAP, and actin which was used as an internal standard, were measured in blots probed at $4{ }^{\circ} \mathrm{C}$ overnight with mouse monoclonal anti-GFAP antibody $(1 \mu \mathrm{g}$ protein per lane; antibody diluted 1:1000; Sigma-Aldrich) and mouse anti-actin monoclonal antibody (antibody diluted 1:1000; Chemicon). In one series of gels, each gel carried duplicate lanes of samples from one control subject and its corresponding age-matched depressed subject (Figure 1). These gels were used to establish whether there was a significant difference in the levels of GFAP between control and depressed subjects. In addition, in another series of gels, 12 subjects from each group were run simultaneously in one gel (Figure 3). The gels with the 12 subjects from each group contained subjects spanning the age range of the entire group. These gels were used to determine whether there was a correlation between the 
levels of GFAP and the age of the subjects at the time of death. After transferring protein to the PVDF membrane, the WesternBreeze ${ }^{\circledR}$ Chemiluminescent Detection Kit was used for detecting immunoreactivity (Invitrogen). The antiGFAP antibody recognizes one protein band at $50 \mathrm{kDa}$ and the anti-actin antibody recognizes one protein band at $42 \mathrm{kDa}$ (Figure 1).

\section{Data Analysis}

The optical density of immunoreactivity in Western blots was quantified by using MCID software (Imaging Research Inc., St Catherines, Ontario). The optical density, defined as the relative optical density $\times$ pixel area, was measured for the bands of interest. There was no significant difference in the net optical density of actin between matched pairs of control and depressed subjects. All of the densitometry measurements were made within the linear range of staining intensities of the film. The level of GFAP protein was defined as the ratio of the optical density value of the GFAP band to the optical density value of the actin band. Duplicate optical density ratios were obtained for each subject and averaged. Student's paired two-tailed $t$-test was used to statistically compare GFAP level, age, and PMI between the control and the depressed groups. Since each matched pair of control and depressed subjects had their duplicate samples run in a single gel, which was separate from those of other pairs, it was not possible to determine correlations between the levels of GFAP and age or other confounding variables. Therefore, we performed an additional experiment in which equal amounts of protein samples from 12 depressed subjects across all ages (or 12 control subjects) were loaded onto a single gel with 12 lanes. Only 12 cases per gel (out of the 15 in each group) were simultaneously run due to the physical limitation in lane space in the electrophoresis-immunoblot apparatus. To ensure that the results obtained when three cases were excluded could be replicated, an additional gel per group was run in which the three cases previously excluded replaced three cases included in the first gel. These three cases were immediately adjacent (in age order) to the subjects previously excluded. Samples from the 12 matching control subjects were run on another gel in the same electrophoresis chamber simultaneously with the other gel containing the MDD samples (same cuvette, electrophoresis solutions, voltage applied and time). The gels from the 12 subjects from each group were incubated with both antiGFAP and anti-actin antibody and the GFAP level was again expressed as the ratio of optical density of GFAP to actin band. It was found that, for the nine cases that were run in both gels, the values of optical density were highly correlated for each group $(r=0.970, p<0.0001$ for MDD subjects, $r=0.912, p<0.001$ for control subjects). Therefore, the 12 values from the first gel and the three remaining values from the second gel (absent in the first gel) were combined to obtain the 15 values for the subjects in each group. These values were used for the analyses reported in the present article. Analyses using the values of the second gel (not reported) produced the same conclusions after statistical analysis.

Correlations between GFAP level, age, PMI, and storage time were calculated in both the control and MDD groups.
In addition, correlations between GFAP level and both onset of depression and duration of depression were assessed in the MDD group. In order to ensure the statistical significance of $p$-values less than 0.05, a Bonferroni correction for five comparisons (GFAP levels compared to age, onset, duration, PMI, and storage time) was applied to Pearson correlation matrices.

\section{RESULTS}

\section{Levels of GFAP}

The level of GFAP for each subject was determined on Western blot as the ratio of the optical density of the GFAP band to the optical density of the actin band (Figure 1). There was no significant difference between control and depressed subjects in the absolute values of optical density for actin $\left(t_{14}=0.47, p=0.65\right)$. Absolute values of optical density for GFAP were found to be significantly lower in the depressed group, as compared to the control group $\left(t_{14}=2.80, p=0.014\right)$. The mean level of GFAP was significantly lower in the depressed group $(0.57 \pm 0.55)$ (mean \pm standard deviation) as compared to that in the control group $\left(1.05 \pm 0.86, t_{14}=2.93, p=0.011\right)$ (Figure 2a). The level of GFAP was lower, by seven-fold on average, in the depressed subject of each matched pair, with the exception of two pairs (Pairs \#11 and \#15, Figure 2). The two depressed subjects in these pairs were older than 70 years of age (Figure 2a and b). There was no significant difference in the level of GFAP between depressed and control subjects older than 60 years of age at the time of death. In contrast, the difference in the level of GFAP between controls and depressed subjects with ages of 60 years or less (Pair \#1 to 9, Figures 2 and 3) was highly significant $\left(t_{8}=3.855, p=0.005\right)$ and reduced by 10 -fold in depression. Therefore, the reduction in the level of GFAP in depressed subjects as compared to age-matched controls was mainly due to the difference observed in subjects younger than 60 years old. On the other hand, two out of the five depressed subjects older than 60 years old had higher levels of GFAP than their matched control subjects.

\section{Correlation of GFAP Levels with Age, Onset of Depression, and Estimated Duration of Depression}

An examination of the levels of GFAP for individual gels of each of the matched pairs suggested that the levels of GFAP were particularly low in the younger subjects in the MDD group. In MDD, GFAP levels were strongly positively correlated with age $(r=0.857, p<0.0001)$ (Figures 3 and $4 a)$. In contrast, in the gel assessing control subjects, there was a tendency for a positive correlation between GFAP levels and age $(r=0.567, p<0.03$; nonsignificant after Bonferroni adjustment) although with a flatter regression line than in the MDD group (Figure $4 \mathrm{~b}$ ).

The age of the depressed subjects was also significantly correlated with the age at the onset of symptoms of depression $(r=0.65, p=0.009)$. A tendency for a positive correlation was found between levels of GFAP and the age at the onset of depression $(r=0.526, p=0.044$, Figure 5a). However, the positive correlation between GFAP level and the duration of depression was nonsignificant $(r=0.398$, 
Table I Characteristics of Subjects

\begin{tabular}{|c|c|c|c|c|c|c|c|}
\hline Control subject $N$ & Age/gender/race & PMI & $\begin{array}{l}\text { Storage time } \\
\text { (months) }^{\mathrm{a}}\end{array}$ & $\begin{array}{l}\text { Cause of } \\
\text { death }\end{array}$ & $\begin{array}{l}\text { Psychotropic } \\
\text { medication }^{\mathrm{b}}\end{array}$ & Drugs/alcohol $^{\mathrm{C}}$ & Toxicology \\
\hline IC & $27 / F / C$ & 15 & 73 & $\mathrm{~N}$ & None & None & None detected \\
\hline $2 c$ & 30/M/AAm & 19 & 63 & $N$ & None & None & None detected \\
\hline $3 c$ & $35 / \mathrm{M} / \mathrm{C}$ & 25 & 66 & $\mathrm{~N}$ & None & None & lidocaine \\
\hline $4 c$ & $37 / F / C$ & 13 & 41 & $N$ & None & None & prochlorperazine \\
\hline $5 c$ & $43 / M / C$ & 23 & 57 & $\mathrm{~N}$ & None & None & $\begin{array}{l}\text { propoxyphene, } \\
\text { norpropoxyphene, } \\
\text { oxycodone }\end{array}$ \\
\hline $6 c$ & $46 / F / C$ & 27 & 77 & $\mathrm{H}$ & None & None & None detected \\
\hline $7 c$ & 46/M/AAm & 11 & 58 & $\mathrm{~N}$ & None & $\begin{array}{l}\text { AA for } 3 \text { years. } \\
\text { Not at the time } \\
\text { of death }\end{array}$ & None detected \\
\hline $8 c$ & $50 / F / C$ & 27 & 65 & $\mathrm{~N}$ & None & None & None detected \\
\hline $9 c$ & 54/M/AAm & 17 & 66 & $\mathrm{~N}$ & clonazepam $^{d}$ & None & brompheniramine \\
\hline $10 c$ & 60/F/AAm & 19 & 85 & $N$ & None & None & None detected \\
\hline IIC & 70/M/C & 29 & 72 & $\mathrm{~N}$ & clonazepam b,e & AA 30 years ago & None detected \\
\hline $12 c$ & $7 / / M / C$ & 24 & 95 & $N$ & None & $\begin{array}{l}\text { AD for } 20 \text { years. } \\
\text { Stopped } 32 \text { yearrs } \\
\text { ago }\end{array}$ & None detected \\
\hline $13 c$ & $77 / M / C$ & 24 & 87 & $\mathrm{~N}$ & None & None & None detected \\
\hline $14 \mathrm{c}$ & $80 / F / C$ & 21 & 58 & $N$ & None & None & None detected \\
\hline $15 c$ & $86 / F / C$ & 18 & 45 & $N$ & None & None & $\begin{array}{l}\text { diltiazem, sodium } \\
\text { 124, potassium } 9.3\end{array}$ \\
\hline Average & $54.1 \pm 18.3$ & & $20.80 \pm 5.21$ & $67.47 \pm 14.98$ & & & \\
\hline
\end{tabular}




\begin{tabular}{|c|c|c|c|c|c|c|c|c|c|}
\hline $\begin{array}{l}\text { Major depressive } \\
\text { disorder subject } N\end{array}$ & $\begin{array}{l}\text { Age/genderl } \\
\text { race }\end{array}$ & PMI & $\begin{array}{l}\text { Storage time } \\
\text { (months) }^{a}\end{array}$ & $\begin{array}{l}\text { Cause of } \\
\text { death }\end{array}$ & $\begin{array}{l}\text { Psychotropic } \\
\text { medication }^{\text {b }}\end{array}$ & Drugs/Alcohol $^{c}$ & Toxicology & $\begin{array}{c}\text { Duration of } \\
\text { depression (years) }\end{array}$ & $\begin{array}{c}\text { Age of } \\
\text { onset }\end{array}$ \\
\hline I & $34 / F / C$ & 27 & 67 & $\mathrm{~S}$ & $\begin{array}{l}\text { trazodone, } \\
\text { alprazolam, } \\
\text { risperidone }\end{array}$ & None & CO, alprazolam & 20 & 14 \\
\hline $2^{g}$ & 30/M/AAm & 18 & 93 & S & None & $\begin{array}{l}\text { AA for } 4 \text { years. } \\
\text { Not at the time } \\
\text { of death }\end{array}$ & $\mathrm{EtOH}$ & 3 & 27 \\
\hline 3 & $36 / \mathrm{M} / \mathrm{C}$ & 11 & 46 & $U$ & None & None & diphenhydramine, & 3 & 33 \\
\hline $4^{h}$ & 40/F/C & 25 & 66 & $\begin{array}{l}\text { HEART, other } \\
\text { acc.OD }\end{array}$ & $\begin{array}{l}\text { temazepam, } \\
\text { fluoxetine }^{\mathrm{b}}\end{array}$ & DA & $\begin{array}{l}\text { mophine, codeine, } \\
\text { hydrocodone, } \\
\text { diphenylhydramine }\end{array}$ & 3 & 35 \\
\hline 5 & $42 / F / C$ & 24 & 89 & S & $\begin{array}{l}\text { fluoxetine, } \\
\text { amitriptyline, } \\
\text { paroxetine, }^{\text {, }} \\
\text { diazepam }^{\mathrm{b}}\end{array}$ & DA & $\begin{array}{l}\text { propoxyphene, } \\
\text { acetaminophen }\end{array}$ & 26 & 15 \\
\hline 6 & $42 / \mathrm{M} / \mathrm{C}$ & 20 & 82 & $\mathrm{~S}$ & sertraline $e^{b}$ & None & $\begin{array}{l}\text { sertraline, } \\
\text { diphenylhydramine }\end{array}$ & 2 & 40 \\
\hline 7 & 46/M/AAm & 17 & 89 & $\mathrm{H}$ & None & None & None detected & I & 45 \\
\hline 8 & 50/F/C & 23 & 82 & $S$ & $\begin{array}{l}\text { clomipramine, } \\
\text { fluoxetine, } \\
\text { thiothixene }\end{array}$ & None & None detected & 4 & 45 \\
\hline 9 & $54 / \mathrm{M} / \mathrm{C}$ & 23 & 89 & Ac & sertraline $e^{b}$ & None & $\begin{array}{l}\mathrm{CO} \text {, phenobarbital, } \\
\text { phenytoin }\end{array}$ & 3 & 51 \\
\hline 10 & 63/F/C & 24 & 88 & $\mathrm{~N}$ & $\begin{array}{l}\text { chlorpromazine, } \\
\text { clonazepam, }^{\text {b }} \\
\text { amitriptyline }^{\mathrm{b}}\end{array}$ & $\begin{array}{l}\text { PS ( } 20 \text { years), } \\
\text { AD( } 25 \text { years })\end{array}$ & & 30 & 33 \\
\hline $11^{8}$ & $73 / F / C$ & 17 & 81 & $N$ & $\begin{array}{l}\text { lithium, } \\
\text { nortriptyline, } \\
\text { restoril, } \\
\text { clonazepamb }^{\text {b }}\end{array}$ & $\begin{array}{l}\text { AD for } 40 \text { years. } \\
\text { Stopped } 8 \text { years } \\
\text { before death }\end{array}$ & None detected & 50 & 23 \\
\hline 12 & $73 / \mathrm{M} / \mathrm{C}$ & 10 & 95 & $\mathrm{~S}$ & nortriptyline ${ }^{b}$ & None & nortriptyline, EtOH & 5 & 69 \\
\hline 13 & $74 / \mathrm{M} / \mathrm{C}$ & 25 & 81 & $\mathrm{~S}$ & $\begin{array}{l}\text { chlorpromazine, } \\
\text { trazodone, } \\
\text { clorazepate, } \\
\text { methylphenidate }\end{array}$ & PS & $\begin{array}{l}\text { diazepam, } \\
\text { acetaminophen }\end{array}$ & 24 & 50 \\
\hline 14 & $78 / F / C$ & 25 & 83 & $\mathrm{~S}$ & lorazepam & None & None detected & 5 & 73 \\
\hline 15 & $86 / \mathrm{M} / \mathrm{C}$ & 21 & 81 & $\mathrm{~s}$ & $\begin{array}{l}\text { fluoxetine, } \\
\text { atenolol }\end{array}$ & None & None detected & 30 & 55 \\
\hline Average & $54.7 \pm 17.6$ & & $20.67 \pm 4.98$ & $80.67 \pm 12.27$ & & & & & \\
\hline
\end{tabular}

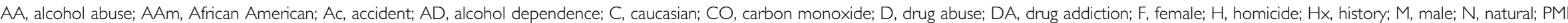
post-mortem interval (hour; defined as the time between death and the beginning of freezing at $-80^{\circ} \mathrm{C}$ ); PS, polysubstance abuse; $\mathrm{S}$, suicide; $\mathrm{U}$, undetermined.

aStorage time refers to the duration between date of the brain tissue being collected for homogenization and the date of death.

brugs that were prescribed in the last month of life.

'Defined as psychoactive substance use disorder.

Prescribed for bursitis, degenerative joint disease, and fibromyalgia.

ePrescribed for restless leg syndrome.

'The duration of illness covers the time between the first display (and not necessarily diagnosis) of symptoms of a depressive illness and the date of death

:This subjects previously met diagnostic criteria for alcohol abuse at 2 and 8 years prior to death.

${ }^{\text {h}}$ Recurrent MD, in full remission. 


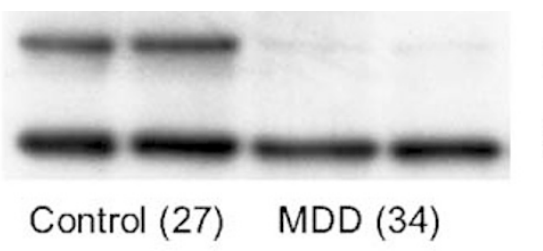

GFAP

Actin

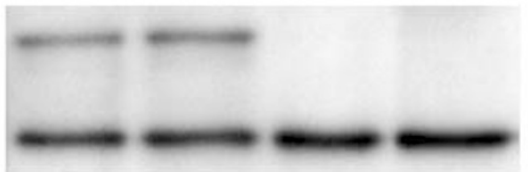

GFAP

Actin

Control (43) MDD (42)

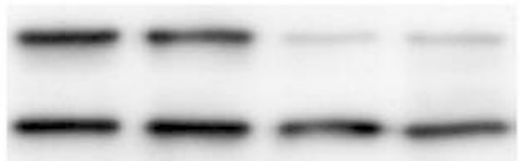

GFAP

Actin

Control (54)

MDD (54)

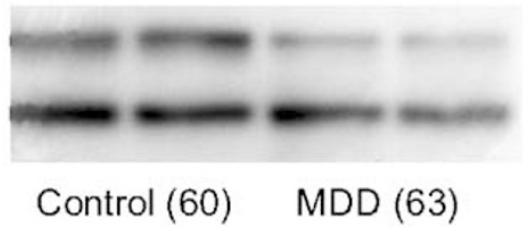

GFAP

Actin

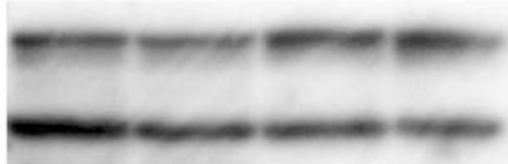

GFAP

Actin

Control (70)

MDD (73)

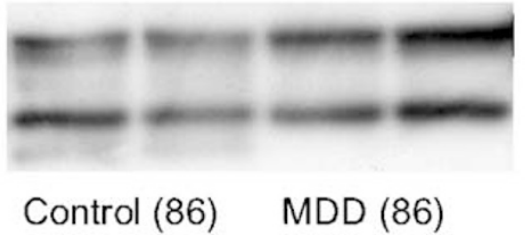

GFAP

Actin

Figure I Blot immunolabeling of GFAP in six pairs of subjects numbered sequentially as Pair \#I, 5, 9, I0, II, and I5 (Table \#I). Two bands were identified as GFAP $(50 \mathrm{kDa})$ and actin $(42 \mathrm{kDa})$. For each pair, control subjects were coupled with depressed subjects in duplicates. The ages of the subjects are indicated in parentheses. Note that GFAP levels from depressed subjects in the younger and middle age pairs are markedly lower than those in control subjects. In contrast, the two depressed subjects over 70 years in the older age group had more GFAP than their matched controls.

$p=0.142$, Figure $5 b)$. Levels of GFAP were not significantly correlated with either PMI (control, $r=-0.107, p=0.704$; MDD, $r=-0.082, p=0.773$ ) or storage time (control, $r=-0.260, p=0.349$; MDD, $r=0.230, p=0.410)$.

There was a significant positive correlation $(r=0.649$ $p=0.003$ ) between levels of GFAP defined in the present study and the values of area fraction of GFAP immunoreactivity measured in our previous study (Miguel-Hidalgo et al, 2000) (Figure 6). a

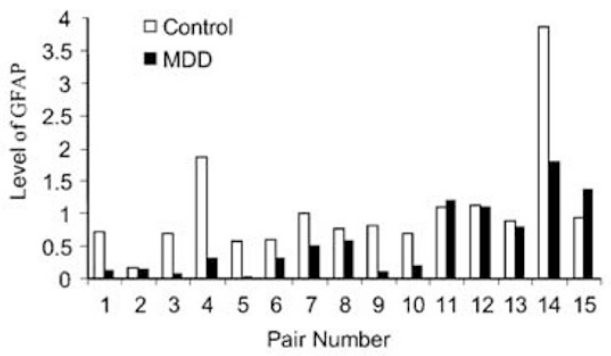

b

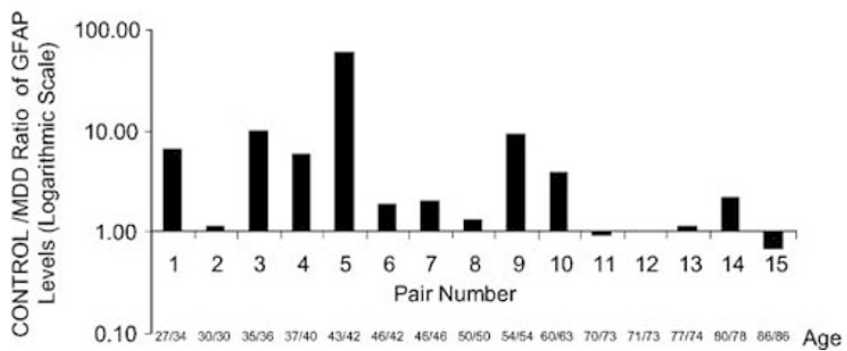

Figure 2 Graph of the optical density ratio of GFAP to actin (GFAP level) for all subjects arranged in pairs of control and depressed subjects. Plot (a) shows the GFAP level of all the subjects grouped by matching pairs. To appreciate the magnitude of the difference in individual pairs, the ratios of GFAP level in the control subject to the level in the matching MDD subject for all pairs are shown in (b) with a logarithmic scale since the GFAP level was as much as 50 times larger in the control than in the MDD subject. Only Pairs \#II and I5 had values lower than I for this intergroup ratio. For each pair, the age to the left of the slash corresponds to the control subject and the age to the right of the slash corresponds to the MDD subject.

\section{a MAJOR DEPRESSION}

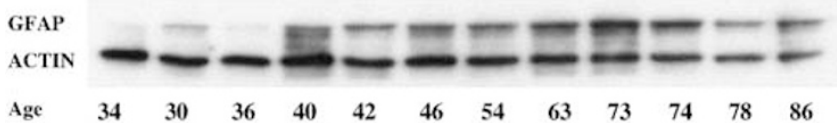

b CONTROL

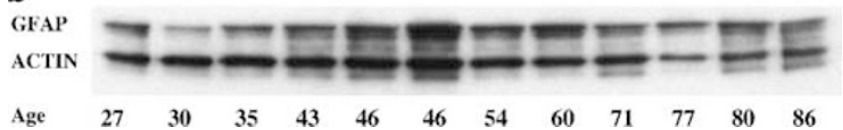

Figure 3 Blot immunolabeling of GFAP and actin bands in 12 depressed subjects (a) and 12 control subjects (b).

\section{DISCUSSION}

The levels of GFAP in the dlPFC, as determined by immunoblotting, are significantly lower in subjects with MDD than in age-matched control subjects. In addition, the levels of GFAP in MDD group show a strong positive correlation with age at the time of death and a trend for a correlation with the age of onset of depression.

Furthermore, after dividing subjects into those less than or greater than 60 years of age at the time of death, the level of GFAP in the depressed group of age less than 60 years was significantly lower, by 10 -fold on average, as compared to age-matched controls. In contrast, there was no significant difference in GFAP levels between the older subjects with MDD and older control subjects. The 


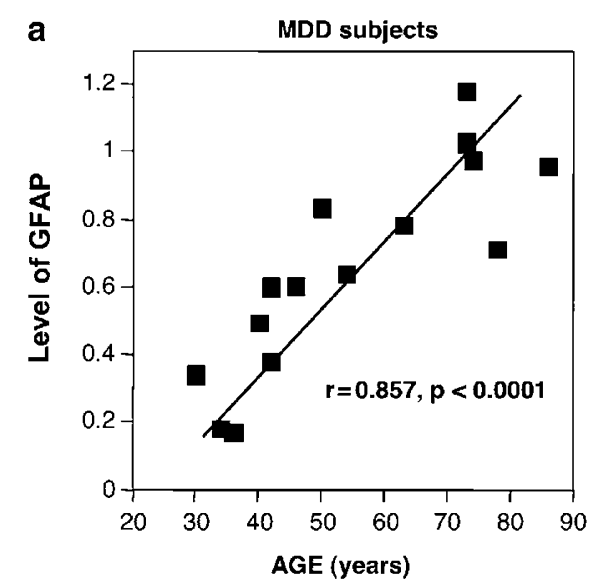

b

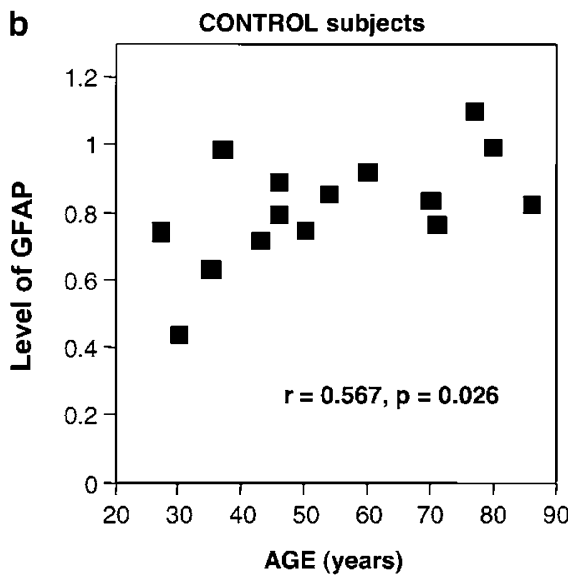

Figure 4 Scatter plots showing positive significant correlations between the level of GFAP and age at the time of death (AGE) in both MDD (a) and control (b) subjects.

significant decrease in the level of GFAP in the dlPFC, in depressed subjects agrees with previous findings of decreased expression of GFAP in other areas of the prefrontal cortex in MDD (Johnston-Wilson et al, 2000; Knable et al, 2001; Webster et al, 2001).

The influence of age on GFAP levels is also consistent with our previous immunohistochemical study of the areal fraction of GFAP immunoreactivity in the dlPFC (MiguelHidalgo et al, 2000). In the immunohistochemical study, areal fraction and packing density of GFAP immunoreactive astrocytes were significantly and positively correlated with age in cortical layers III-V of the dlPFC in depressed subjects. In control subjects, the areal fraction of GFAP was correlated with age in layer III and IV but not in layer V. In agreement with these findings, the present study shows a strong positive correlation of GFAP levels with age in the depressed group but only a trend for such a correlation in the control group. In fact, for those subjects included in both our previous morphometric study (Miguel-Hidalgo et al, 2000), and in the present investigation, we found a significant positive correlation between GFAP area fraction in cortical layers III + IV and the level of GFAP in the gray matter. In that previous study we found that comparing control and MDD subjects at ages less than 45 years revealed a marked reduction in the area fraction of GFAP immunoreactivity in MDD subjects. In the present study of
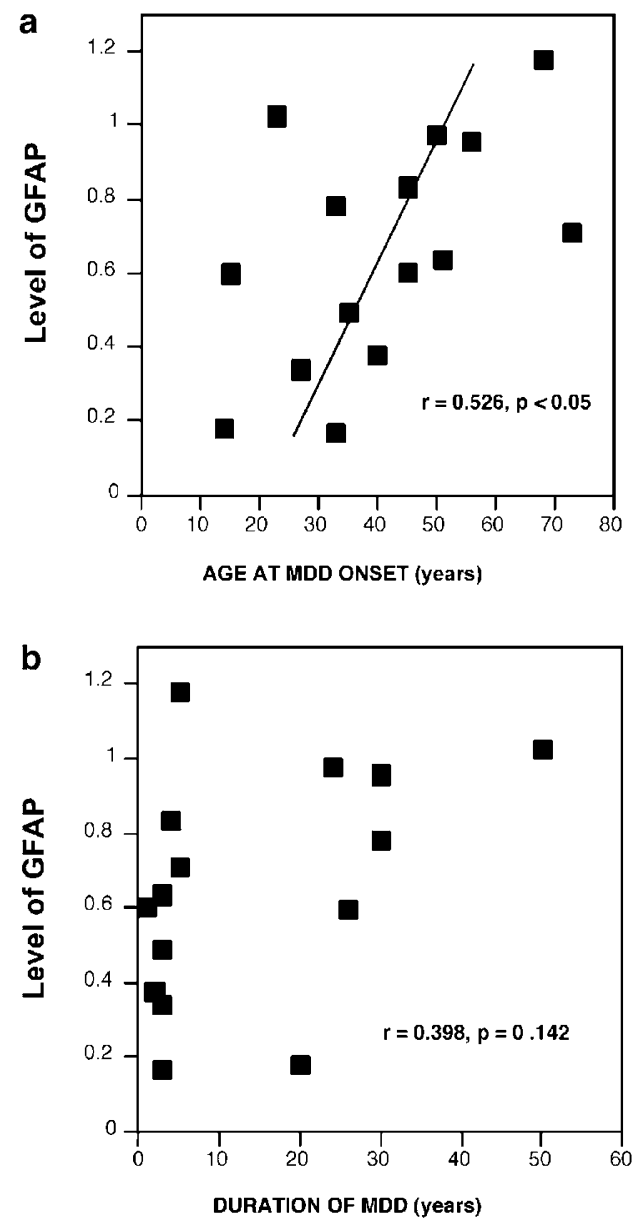

Figure 5 Scatter plots showing the correlation between level of GFAP and age of onset of depression (a) and the estimated duration of depression (b) in the MDD group. The correlation with age of onset was positive although it was not significant after Bonferroni adjustment.

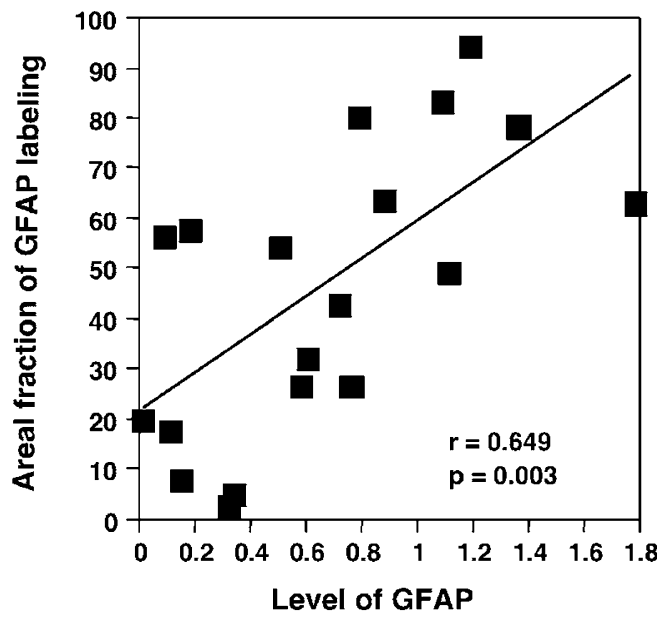

Figure 6 Scatter plot showing the correlation between the levels of GFAP measured from Western blots and the area fraction of GFAP immunoreactivity in histological sections for cortical layers III + IV of area 9 Both parameters were available from I4 MDD subjects and five controls subjects. 
GFAP levels, comparing subjects that were 45 years old at the time of death also produced a significant difference in the level of GFAP. In fact, at any age less than 60 years such a grouping would have revealed such significant difference in GFAP levels between the groups. One possibility for the extended age range at which GFAP levels appear to still be significantly lower in MDD subjects is that in order to optimize pair-matching, we substituted 10 of the control subjects in the previous study with as many new control subjects in the present study and that chance variation would account for the shifted cutoff age. However, in both studies there is clearly a steeper correlation of GFAP levels and age in the MDD group than in the control group, and the younger MDD subjects in both studies systematically have lower values of GFAP parameters than the control subjects. A parsimonious explanation for the difference in the cutoff age would be that around 60 years of age appears to mark the time when an increase in GFAP levels might occur in MDD patients that make those levels comparable to the levels in control subjects. On the other hand, the parameters measured in our previous study are of a morphometric nature and they not only depend on the intensity of immunostaining but also on the shape, number and extent of astrocytes processes, and on the number of astrocytes themselves. Accordingly, it is possible that some morphological changes in astrocytes occur earlier (or at different pace) than changes in the level of GFAP in gray matter. These changes might affect the measured area fraction of GFAP (morphometric measurement) without significantly altering the level of GFAP (biochemical measurement). Further studies at the level of individual astrocytes are necessary to determine the relationship of morphological changes in astrocytes and changes in the expression of GFAP.

In congruence with significantly higher amounts of GFAP in the prefrontal cortex in older people with depression, Davis et al (2002) reported an increase in areal fraction of GFAP immunoreactivity in cortical layer I of dlPFC in older depressed subjects and no changes in the remaining cortical layers as compared to older controls. It has also been demonstrated that the levels of mRNA for GFAP increase with age in the human brain (Nichols et al, 1993). In this study, significant increases in the levels of mRNA for GFAP were found in the hippocampus, frontal (Brodmann's areas 9 and 10) and temporal cortex (areas 21, 22, and 38) in older (60-79 years) subjects as compared to younger (25-59 years) subjects. The protein levels of GFAP were also significantly correlated with age in frontal cortex (areas 9 and 44) and hippocampus in another cohort of human subjects (David et al, 1997). However, in another study a similar correlation was not found in non-neuropsychiatric control subjects in several brain regions including entorhinal cortex, midfrontal cortex, and orbital frontal cortex (Arnold et al, 1996). The discrepancy in the effect of age in the above studies may be due to different cohorts, or an insufficient number of subjects used. In addition, the span of ages examined in other studies may have not been broad enough to establish the correlation between GFAP levels and age at the time of death.

The question remains as to why younger depressed subjects have significantly lower levels of GFAP than agematched controls or older depressed subjects. It could be suggested that, for some older subjects with early onset of depression (for example, the depressed subject in pair \#11), aging-associated processes might have ultimately increased GFAP expression to near or higher than the levels in agematched control subjects. Alternatively, since the age of depressed subjects is correlated with the age of onset of depression, it is also possible that the involvement of GFAP expression in early $v s$ late life depression differs because the underlying pathophysiology in early life depression is different from that in late life depression. Increasing clinical evidence suggests that late-onset depression (first depressive episode when older than 50 years) differs from earlyonset depression by its etiology, phenomenology, and cerebrovascular pathology (Heun et al, 2000; Krishnan et al, 1995; Lavretsky et al, 1998).

As many of the MDD subjects in the present study were being treated with psychotropic medications, an argument could be made that these medications may influence the level of GFAP. However, in the three pairs (pairs 3, 4, and 7) in which the MDD subject was not receiving psychotropic medication, the level of GFAP in each subject was also several-fold lower than in the matching control, suggesting that if psychotropic medication exerts any effect on GFAP levels, these effects may not be distinguishable from the effects of depression. Alcohol and drug abuse may have had an effect on GFAP expression; however, in the present study, very few subjects in the MDD and control groups were found to have had alcohol or drug abuse, and in the majority of these cases it was not current. This suggests that the reduced level of GFAP in the MDD subjects included in the present study was not related to those forms of abuse.

The reduction in the packing density of glial cells previously detected in younger depressives (Miguel-Hidalgo et $a l, 2000$ ) suggests that a decline in the numbers of astrocytes might contribute to the reduction of GFAP levels. On the other hand, a reduction in glial activity suggested by reduction in the expression of GFAP without substantial changes in the numbers of astrocytes cannot be ruled out. These reductions in glial density may be a result of disease progression or may be secondary to neuronal malfunction. Although it is premature to favor any etiopathological hypothesis regarding glial involvement in depression, some data appear to be consistent with the possibility of a direct influence of glial changes in the establishment of depression (reviewed in Cotter et al, 2002b). It is also possible that hereditary or developmental factors result in populations of glial cells that are reduced in number or impaired in function, which may be a factor in hastening the onset of depression. For instance, post-mortem studies report a more substantial reduction of glial numbers or packing density in MDD subjects with a family history of mood disorder than in those without such a history (Ongur et al, 1998; Rajkowska et al, 1999). Other intriguing evidence to support the possibility of astroglia-related hereditary factors in depression is the presence of a polymorphism in the GFAP gene in a rare disease with familial Parkinsonism and mental depression (Comings, 1982).

Environmental factors, in addition to hereditary conditions, may affect the level of GFAP in the brain and contribute to disease progression or onset. For instance, low-level exposure of rat to lead at various developmental periods is associated with changes in levels of GFAP protein 
and mRNA in the adult hippocampus (Stoltenburg-Didinger et al, 1996). Exposure to lead after brain development results in increases in GFAP protein and mRNA. Exposure to lead before development of the brain revealed a lower level of expression of mRNA for GFAP. GFAP expression is also lowered by human hepatic encephalopathy (Kimura and Budka, 1986; Kril et al, 1997). Although these studies show the possibility of pathological reductions in the expression of GFAP, it remains to be determined whether depression might be associated with environmentally altered expression of GFAP.

\section{ACKNOWLEDGEMENTS}

We gratefully acknowledge the work of James C Overholser, PhD, Herbert Y Meltzer, MD, Bryan Roth, MD, PhD, and George Jurjus, MD, Ginny Dilley and Lisa Konick in the retrospective psychiatric diagnoses. The excellent assistance of the Cuyahoga County Coroner's Office, Cleveland, $\mathrm{OH}$, is greatly appreciated. This work was supported by grants from the National Institute of Mental Health (MH63187, MH61578 and MH60451).

\section{REFERENCES}

Arnold SE, Franz BR, Trojanowski JQ, Moberg PJ, Gur RE (1996). Glial fibrillary acidic protein-immunoreactive astrocytosis in elderly patients with schizophrenia and dementia. Acta Neuropathol (Berl) 91: 269-277.

Comings DE (1982). Two-dimensional gel electrophoresis of human brain proteins. III. Genetic and non-genetic variations in 145 brains. Clin Chem 28: 798-804.

Cotter D, Mackay D, Chana G, Beasley C, Landau S, Everall IP (2002a). Reduced neuronal size and glial cell density in area 9 of the dorsolateral prefrontal cortex in subjects with major depressive disorder. Cereb Cortex 12: 386-394.

Cotter D, Mackay D, Landau S, Kerwin R, Everall I (2001). Reduced glial cell density and neuronal size in the anterior cingulate cortex in major depressive disorder. Arch Gen Psychiatry 58: 545-553.

Cotter D, Pariante C, Rajkowska G (2002b). Glial pathology in major psychiatric disorders. In Agam G, Belmaker RH, Everall I (eds). The Post-Mortem Brain in Psychiatric Research. Kluwer Academic Publishers: Boston. pp 291-324.

Damadzic R, Bigelow LB, Krimer LS, Goldenson DA, Saunders RC, Kleinman JE et al (2001). A quantitative immunohistochemical study of astrocytes in the entorhinal cortex in schizophrenia, bipolar disorder and major depression: absence of significant astrocytosis. Brain Res Bull 55: 611-618.

David JP, Ghozali F, Fallet-Bianco C, Wattez A, Delaine S, Boniface B et al (1997). Glial reaction in the hippocampal formation is highly correlated with aging in human brain. Neurosci Lett 235: 53-56.

Davis S, Thomas A, Perry R, Oakley A, Kalaria RN, O’Brien JT (2002). Glial fibrillary acidic protein in late life major depressive disorder: an immunocytochemical study. J Neurol Neurosurg Psychiatry 73: 556-560.
Heun R, Kockler M, Papassotiropoulos A (2000). Distinction of early- and late-onset depression in the elderly by their lifetime symptomatology. Int J Geriatr Psychiatry 15: 1138-1142.

Johnston-Wilson NL, Sims CD, Hofmann JP, Anderson L, Shore $\mathrm{AD}$, Torrey EF et al (2000). Disease-specific alterations in frontal cortex brain proteins in schizophrenia, bipolar disorder, and major depressive disorder. The Stanley Neuropathology Consortium. Mol Psychiatry 5: 142-149.

Kimura T, Budka H (1986). Glial fibrillary acidic protein and S-100 protein in human hepatic encephalopathy: immunocytochemical demonstration of dissociation of two glia-associated proteins. Acta Neuropathol (Berl) 70: 17-21.

Knable MB, Torrey EF, Webster MJ, Bartko JJ (2001). Multivariate analysis of prefrontal cortical data from the stanley foundation neuropathology consortium. Brain Res Bull 55: 651-659.

Kril JJ, Flowers D, Butterworth RF (1997). Distinctive pattern of Bergmann glial pathology in human hepatic encephalopathy. Mol Chem Neuropathol 31: 279-287.

Krishnan KR, Hays JC, Tupler LA, George LK, Blazer DG (1995). Clinical and phenomenological comparisons of late-onset and early-onset depression. Am J Psychiatry 152: 785-788.

Lavretsky H, Lesser IM, Wohl M, Miller BL (1998). Relationship of age, age at onset, and sex to depression in older adults. Am J Geriatr Psychiatry 6: 248-256.

Miguel-Hidalgo JJ, Baucom C, Dilley G, Overholser JC, Meltzer HY, Stockmeier CA et al (2000). Glial fibrillary acidic protein immunoreactivity in the prefrontal cortex distinguishes younger from older adults in major depressive disorder. Biol Psychiatry 48: 861-873.

Nichols NR, Day JR, Laping NJ, Johnson SA, Finch CE (1993). GFAP mRNA increases with age in rat and human brain. Neurobiol Aging 14: 421-429.

Ongur D, Drevets WC, Price JL (1998). Glial reduction in the subgenual prefrontal cortex in mood disorders. Proc Natl Acad Sci USA 95: 13290-13295.

Rajkowska G (2003). Depression: what we can learn from postmortem studies. Neuroscientist 9: 273-284.

Rajkowska G, Goldman-Rakic PS (1995). Cytoarchitectonic definition of prefrontal areas in the normal human cortex: I. Remapping of areas 9 and 46 using quantitative criteria. Cereb Cortex 5: 307-322.

Rajkowska G, Halaris A, Selemon LD (2001). Reductions in neuronal and glial density characterize the dorsolateral prefrontal cortex in bipolar disorder. Biol Psychiatry 49: 741-752.

Rajkowska G, Miguel-Hidalgo JJ, Wei J, Dilley G, Pittman SD, Meltzer HY et al (1999). Morphometric evidence for neuronal and glial prefrontal cell pathology in major depression. Biol Psychiatry 45: 1085-1098.

Stoltenburg-Didinger G, Punder I, Peters B, Marcinkowski M, Herbst $\mathrm{H}$, Winneke $\mathrm{G}$ et al (1996). Glial fibrillary acidic protein and RNA expression in adult rat hippocampus following lowlevel lead exposure during development. Histochem Cell Biol 105: 431-442.

Webster MJ, Knable MB, Johnston-Wilson N, Nagata K, Inagaki M, Yolken RH (2001). Immunohistochemical localization of phosphorylated glial fibrillary acidic protein in the prefrontal cortex and hippocampus from patients with schizophrenia, bipolar disorder, and depression. Brain Behav Immun 15: 388-400. 